\title{
Erratum to: An Integrated Linear Reconstruction for Finite Volume Scheme on Unstructured Grids
}

\author{
Li Chen ${ }^{1} \cdot \operatorname{Ruo~Li}{ }^{2}$
}

Published online: 13 April 2016

(C) Springer Science+Business Media New York 2016

\section{Erratum to: J Sci Comput DOI 10.1007/s10915-016-0173-1}

The original version of this article unfortunately contained a mistake. The presentation of Fig. 8a-d was incorrect. The corrected Fig. 8a-d is provided here.

The online version of the original article can be found under doi:10.1007/s10915-016-0173-1.

$\bowtie$ Ruo Li

rli@math.pku.edu.cn

Li Chen

cheney@pku.edu.cn

1 School of Mathematical Sciences, Peking University, Beijing 100871, China

2 CAPT, LMAM and School of Mathematical Sciences, Peking University, Beijing 100871, China

黛 Springer 


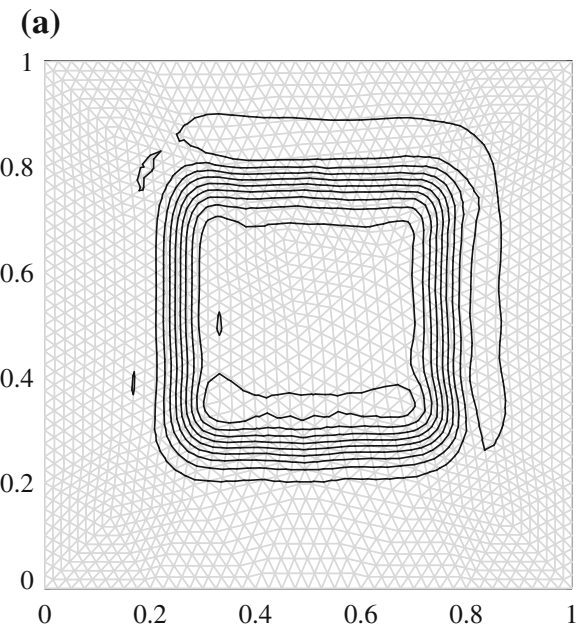

(b)

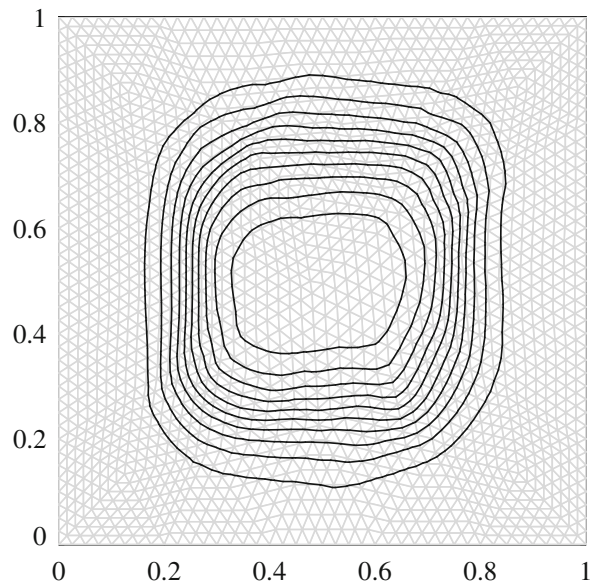

(c)

(d)
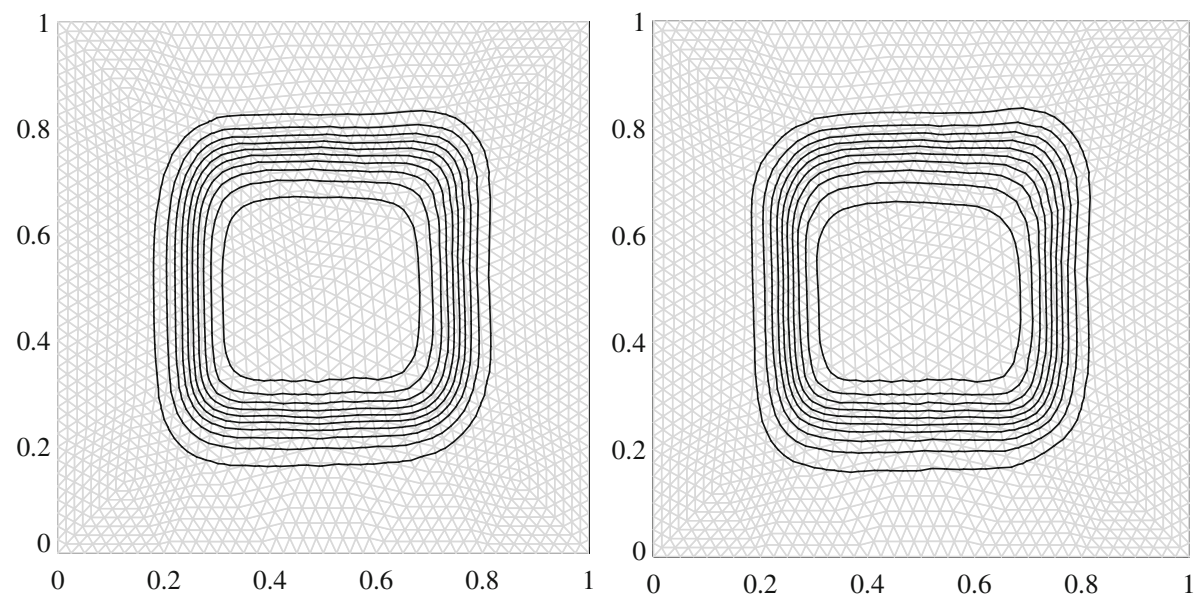

Fig. 8 Contours of the square wave at $t=1$ with 3968 cells. a Unlimited. b SSL. c RSL. d ILR 